\title{
Produção científica dos pesquisadores dos Programas de Pós- graduação em Aquicultura no Brasil: uma análise das publicações periódicas científicas no período de 2009 a 2011
}

Discente: Giani Kurtz Alegria

Orientadora: Dra. Ursula Blattmann - PGCIN/UFSC

Coorientador: Dr. Adilson Luiz Pinto - PGCIN/UFSC

Banca: Dr. Luis Alejandro Vinatea Arana - PPG-AQI/UFSC

Dra. Edna Lúcia da Silva - PGCIN/UFSC

Dr. Sérgio Winckler da Costa - EPAGRI

\section{RESUMO}

A produção científica pode ser considerada um indicador do status quo de uma área do conhecimento, e em um nível macro, da ciência e tecnologia de um país. Esta pesquisa teve como objetivo analisar a produção periódica científica dos pesquisadores dos cursos de pós-graduação em Aquicultura no Brasil. A abordagem da pesquisa é quantitativa e a natureza das fontes utilizadas para compor este estudo, pode ser classificada como documental. Quanto aos objetivos, é exploratória e explicativa. A pesquisa realizada mapeou a produção de artigos científicos dos professores dos programas de pós-graduação em Aquicultura no Brasil, no período de 2009 a 2011. Ao total foram pesquisados 8 programas, dos quais 5 pertencem a instituições federais, 2 são estaduais e 1 pertence a uma instituição particular. Constam como professores permanentes dos programas 136 pesquisadores, e com base nas informações do currículo Lattes de cada um deles, foram extraídas as informações que deram origem a este estudo. As conclusões mostraram que a publicação de artigos apresentou-se bem distribuída entre os pesquisadores, entretanto poucos pesquisadores foram responsáveis por quase metade do total de publicações. Há uma relação existente entre produção, coautoria e visibilidade em praticamente todos os programas, entretanto este não é um fator que determina que os mais produtivos tenham maior visibilidade. A região Sudeste apresentou o maior número de publicações, e a região Sul obteve maior visibilidade de seus artigos. 0 idioma principal das publicações é o inglês. Os programas da UNESP, da FURG e do IP foram os que mais publicaram artigos. Os programas que tiveram maior visibilidade (UNESP, FURG e UFSC) foram os que mais publicaram artigos no idioma inglês e os que mais publicaram em periódicos que possuem Fator de Impacto $>2,000$, considerados A1 na área de Zootecnia e Recursos Pesqueiros. 